\title{
Dissolution of indium arsenide in nitric solutions of the hydrobromic acid
}

\author{
Z. F. Tomashik, S. G. Danylenko, and V. N. Tomashik \\ Institute of Semiconductor Physics, National Academy of Sciences of Ukraine, Kyiv, 252028, Ukraine, \\ tel. +380 (44) $265-5755$
}

\begin{abstract}
Dissolution of InAs in $\mathrm{HNO}_{3}-\mathrm{HBr}-\mathrm{H}_{2} \mathrm{O}$ solutions is studied. The surface of equal etching rates is constructed, and the limiting stages of the dissolution process are determined. Depending on the $\left[\mathrm{HNO}_{3}\right] /[\mathrm{HBr}]$ ratio, InAs dissolution may be limited by kinetic, or diffusion, or combined mechanisms. The dissolution rate of InSb in these solutions is rather low, and the etched surface is covered with a friable sediment. $\mathrm{HNO}_{3}-\mathrm{HBr}-\mathrm{H}_{2} \mathrm{O}$ solutions can be employed for a dynamic chemical polishing of InAs with a variable etching rate.
\end{abstract}

Keywords: dissolution, etchant, indium arsenide, nitric acid, hydrobromic acid, diffusion stage, kinetic limitations.

Paper received 23.11.98; revised manuscript received 13.04.99; accepted for publication 19.04.99.

\section{Introduction}

Bromine-containing etchants are widely used for treatment of III-V semiconducting compounds because of the unique combination of the oxidizing and complexing properties of elementary bromine and the softness of the oxidizing action in comparison to that of other oxidants. The products of oxidation are bromides that can be easily dissolved in water and many organic solvents. Even at a low concentration of bromine, the surface of the crystal under dissolution is covered with a rather thin and dense film formed from the reaction products, so that the process of dissolution is moved to the diffusion region (in contrast to the case of acid etchants, when the surface is covered with a porous oxide film, which may be hardly soluble and, in such manner hampers the process of further oxidation) $[1,2]$. Solutions of bromine in methanol are employed most of all; however, a wider use of this type of etchants in industry and laboratories is restricted by the high toxicity of both components. Substitution of methanol with other organic solvents dramatically impairs the polishing properties of the etchant, while using aqueous solutions of $\mathrm{HBr}$ as bromine solvents does not solve the problem of etchants toxicity, too.

According to [2], the rate of InP, InAs and GaAs dissolution grows linearly with the rise of $\mathrm{Br}_{2}$ concentration in methanol. The quality of the etched surface essentially depends on the concentration of $\mathrm{Br}_{2}$. Stirring of brominemethanol solutions significantly affects the dissolution rate, especially at small concentrations of $\mathrm{Br}_{2}$. A solution of $\mathrm{Br}_{2}$ in dimethylformamide may be used for local dissolution of GaAs and InP [3], HBr-containing solutions - for a profile etching of GaAs [4], while solutions of saturated bromic water in $\mathrm{HBr}$ are recommended for fabrication of submicron circuits on the surface of InP and InGaAsP crystals [5]. According to [6], indium phosphide is solvable both in solutions of $\mathrm{Br}_{2}$ in $\mathrm{HBr}$ and in the hydrobromic acid itself, while solutions of the $\mathrm{HNO}_{3}$ $\mathrm{HBr}$ system can be used for structural etching of InP [7].

\section{Results and discussion}

In the present work, the kinetics of InAs dissolution in solutions of the $\mathrm{HNO}_{3}-\mathrm{HBr}-\mathrm{H}_{2} \mathrm{O}$ system is studied in reproducible hydrodynamic conditions using a rotating disk. The initial components of the above-mentioned compounds interact with one another to produce nitrosyl bromide and bromine: 


\section{Z. F. Tomashik et al.: Dissolution of indium arsenide in nitric solutions of ...}

$\mathrm{HNO}_{3}+3 \mathrm{HBr}=\mathrm{NOBr}+\mathrm{Br}_{2}+2 \mathrm{H}_{2} \mathrm{O}$

$2 \mathrm{NOBr}=\mathrm{Br}_{2}+2 \mathrm{NO}$

$\mathrm{HNO}_{3}+3 \mathrm{HBr}=\mathrm{NO}_{2}+\mathrm{Br}_{2}+\mathrm{H}_{2} \mathrm{O}$

Depending on the $\left[\mathrm{HNO}_{3}\right] /[\mathrm{HBr}]$ ratio in a particular solution, the bromine evolved may be dissolved in the excess $\mathrm{HBr}$ to form etching mixtures similar in composition and properties to $\mathrm{Br}_{2}$ solutions in $\mathrm{HBr}$. Alternatively (in the case of $\left[\mathrm{HNO}_{3}\right] /[\mathrm{HBr}]<0.9$ ), it can evolve from the solution [8]. The more elementary bromine is accumulated in the solution, the faster is the subsequent evolution of bromine, and the sooner is the equilibrium achieved (3). This suggests a chain-like mechanism of the interaction. In the case of $\left[\mathrm{HNO}_{3}\right] /[\mathrm{HBr}]>0.8$, the growth of the bromine concentration stops, and the equilibrium is achieved at the room temperature as early as in 5 to $10 \mathrm{~min}$ after $\mathrm{Br}_{2}$ first emerges in the solution. On the other hand, in the case of $\left[\mathrm{HNO}_{3}\right] /[\mathrm{HBr}]<0.1$, the equilibrium is achieved no sooner than in $60 \mathrm{~min}$, depending on the temperature, illumination level, and some other factors. In the presence of excess $\mathrm{HBr}$, bromine is bound in the solution almost completely, because of the following reactions:

$\mathrm{Br}_{2}+\mathrm{Br}^{-} \Leftrightarrow \mathrm{Br}_{3}$

$2 \mathrm{Br}_{2}+\mathrm{Br}^{-} \Leftrightarrow \mathrm{Br}_{5}$

The rate constants for reactions (4) and (5) are 0.051 and 0.0246 , respectively [6]. Therefore, the kinetics and mechanism of InAs dissolution in solutions enriched with $\mathrm{HBr}$ or $\mathrm{HNO}_{3}$ should be essentially different, similarly to the case of CdTe dissolutions in solutions of the same kind [8].

The experiments were performed using single-crystal n-type InAs wafers cut from ingots perpendicularly to $<111>$ direction, with the surface area of about $0.5 \mathrm{~cm}^{2}$ and thickness of 1.5 to $2 \mathrm{~mm}$, charge carrier concentration $5 \cdot 10^{16} \mathrm{~cm}^{-3}$ and mobility $30000 \mathrm{~cm}^{2} / \mathrm{V} \cdot \mathrm{s}$. Prior to the etching, the wafers were mechanically polished, and the surface layer of 50 to $80 \mu \mathrm{m}$ was removed with the etchant of the same composition as that subsequently used for studies of the etching process. The samples were attached to quartz substrates using pizzeine or BF-2 glue and then mounted in a teflon holder allowing measurements in the rotating disk mode (with the rotation rate ranging from 36 to $120 \mathrm{rpm}$ ). The etching rate was determined by the wafer thickness reduction using ICh-1 time indicator. Two or three samples were etched simultaneously, with differences in the measured thickness not exceeding $5 \%$. Before etching, all etchants were allowed to stand for 40 to $60 \mathrm{~min}$ since the first emergence of bromine. The solutions were prepared using $70 \%$ extra grade $\mathrm{HNO}_{3}, 49 \%$ reagent-grade $\mathrm{HBr}$ and distilled water.

The process of etching is quantitatively characterized by the rate of sample dissolution. Fig. 1 shows the diagram of the InAs etching rate $(\mu \mathrm{m} / \mathrm{min})$ vs the $\mathrm{HNO}_{3}$ $\mathrm{HBr}-\mathrm{H}_{2} \mathrm{O}$ etchant composition built using the simplex method of mathematical planning of the experiment. It is seen from this figure that addition to $\mathrm{HNO}_{3}$ a small amount of $\mathrm{HBr}$ somewhat increases the InAs dissolution rate, which can be explained by the effect of reactions (1-3) taking place. Then, the dissolution rate passes the maximum and starts to decrease. Similarly to the case of CdTe dissolution in solutions of the same type [8], this behavior can be explained by the electrochemical mechanism of InAs dissolution in $\mathrm{HNO}_{3}$. The reactions of the cathodic reduction of $\mathrm{HNO}_{3}$ and anodic dissolution of InAs are coupled, and the rate of a process of this kind is usually limited with the cathodic reaction, which, in its turn, is self-catalyzed (the catalytic agent is $\mathrm{HNO}_{2}$ ). In an acid ambient, $\mathrm{HBr}$ interacts with the nitrous acid $\left(2 \mathrm{HBr}+2 \mathrm{HNO}_{2}=2 \mathrm{NO}+\mathrm{Br}_{2}+2 \mathrm{H}_{2} \mathrm{O}\right)$, thus sharply reducing the concentration of the catalyst and slowing down the entire process. Depending on the $\left[\mathrm{HNO}_{3}\right] /[\mathrm{HBr}]$ ratio in the solution, the effect of this interaction on the dissolution rate will be different. In the case of InAs dissolution in $\mathrm{HNO}_{3}-\mathrm{HBr}-\mathrm{H}_{2} \mathrm{O}$, this effect is the most pronounced when $\left[\mathrm{HNO}_{3}\right] /[\mathrm{HBr}] \approx 1$. When this ratio is lower or higher, the process of dissolution is significantly affected by the interaction between the components of the etchant according to the reactions (1-3). As a result of this interaction, the highest rates of InAs dissolution are observed in the area of $\mathrm{HBr}$-enriched solutions, because this is where the largest amount of elementary bromine is evolving, and the process of InAs dissolution is eventually taking place in the solutions of the $\mathrm{Br}_{2}-\mathrm{HBr}$ system.

For some solutions of the $\mathrm{HNO}_{3}-\mathrm{HBr}-\mathrm{H}_{2} \mathrm{O}$ system (points II, III and IV in Fig. 1,a), the dependences of the

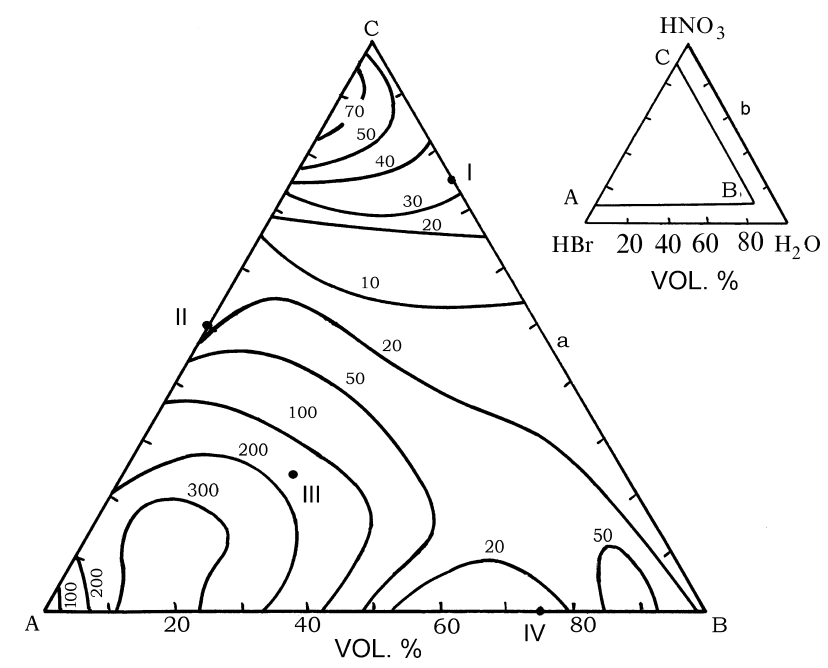

Fig. 1. The surface of equal etching rates $(\mu \mathrm{m} / \mathrm{min})$ of $I n A s$ in $\mathrm{HNO}_{3}-\mathrm{HBr}-\mathrm{H}_{2} \mathrm{O}$ solutions (a) in the composition range $A-B-C$. At the nodes $A, B$ and $C$, the ratio of $49 \% \mathrm{HBr}$ : $70 \% \mathrm{HNO}_{3}: \mathrm{H}_{2} \mathrm{O}$ is as follows (in vol. \%): $A-90: 10: 0$; $B-10: 10: 80 ; C-10: 90: 0$; temperature: $24^{\circ} \mathrm{C}$, disk rotation rate: $120 \mathrm{~min}^{-1}$ ). 


\section{Z. F. Tomashik et al.: Dissolution of indium arsenide in nitric solutions of ...}

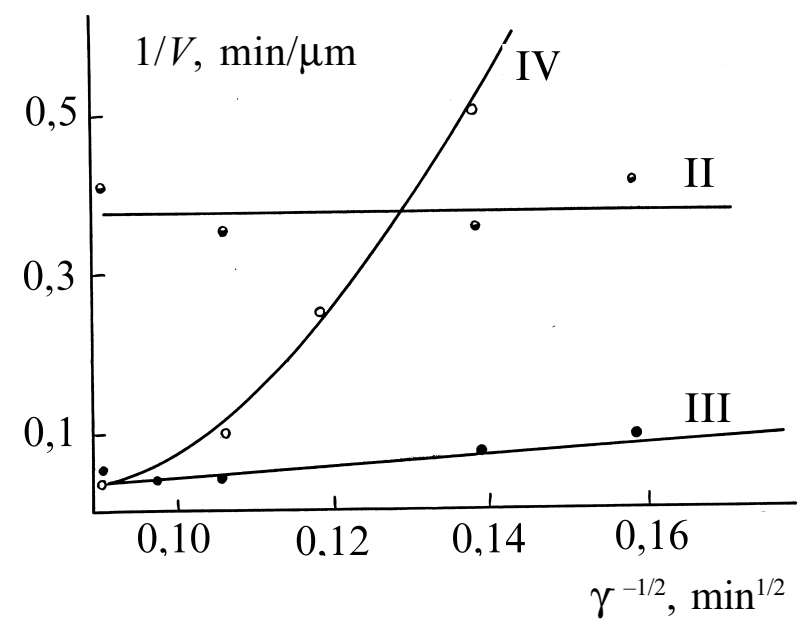

Fig. 2. Dependence of the InAs dissolution rate on the mixing rate for the solutions II, III and IV of the $\mathrm{HNO}_{3}-\mathrm{HBr}-\mathrm{H}_{2} \mathrm{O}$ system (the composition of the solutions II, III and IV is indicated in Fig. 1,a).

dissolution rate $(V)$ on the disk rotation rate $(\gamma)$ are plotted as $V^{-1}$ vs $\gamma^{1 / 2}$. Curves of this type may elucidate the character of the processes underlying the dissolution [1, 2]. When the process is diffusion-limited, the curve should pass through the coordinate origin. A larger role of the surface (chemical) reaction in the entire process of the dissolution results in a smaller slope of the line, and in the case of the process limited by the rate of the chemical reaction, the line becomes parallel to the $X$-axis. When the process has a combined mechanism, the line or its extrapolation cuts off a certain portion of the $Y$-axis, whose length allows the rate constant of the overall chemical reaction to be calculated.

It can be seen from Fig. 2 that, depending on the composition of the solution, the process of InAs dissolution in $\mathrm{HNO}_{3}-\mathrm{HBr}-\mathrm{H}_{2} \mathrm{O}$ solutions is limited by kinetic (solution II) or diffusion (solution III) restrictions, or has a combined mechanism (solution IV). In other words, enrichment of the solutions with the nitric acid moves the dissolution process to the kinetic region, while enrichment with $\mathrm{HBr}$ and $\mathrm{H}_{2} \mathrm{O}$ gradually moves it to the diffusion region. This conclusion is supported also by the temperature dependences of the process of InAs dissolution in these solutions (Fig. 3). For example, dissolution of InAs in $\mathrm{HNO}_{3}$-enriched solutions is indeed limited by the kinetic stage, since the apparent activation energy of the overall process $\left(E_{a}\right)$ is $58 \mathrm{~kJ} / \mathrm{mol}$ (Fig. 3, curve I). As the content of $\mathrm{HBr}$ and $\mathrm{H}_{2} \mathrm{O}$ in the solutions increases, the process of dissolution moves to the diffusion region, because the apparent activation energy is reduced to 39 $40 \mathrm{~kJ} / \mathrm{mol}$ (Fig. 3, curve III).

The experimental data obtained by us made it possible to identify the range of concentrations that can be used for dynamic chemical polishing of InAs with a variable etching rate.

Our experiments on InSb dissolution in nitric solutions of the hydrobromic acid have not given any positive results because of the insignificant solubility of indium antimonide in solutions of this type. This is one more justification of the fact that bromine-containing etchants are seldom used in technological pre-processing of InSb surface for device fabrication [1, 2]. This behavior of $\mathrm{InSb}$ in the solutions under study can be explained by the decomposition of $\mathrm{SbBr}_{3}$, which is formed in the process, under the action of the nitric acid, with simultaneous oxidation of $\mathrm{Sb}^{+3}$ to $\mathrm{Sb}^{+5}$ [9], and passivation of the surface with the compounds formed.

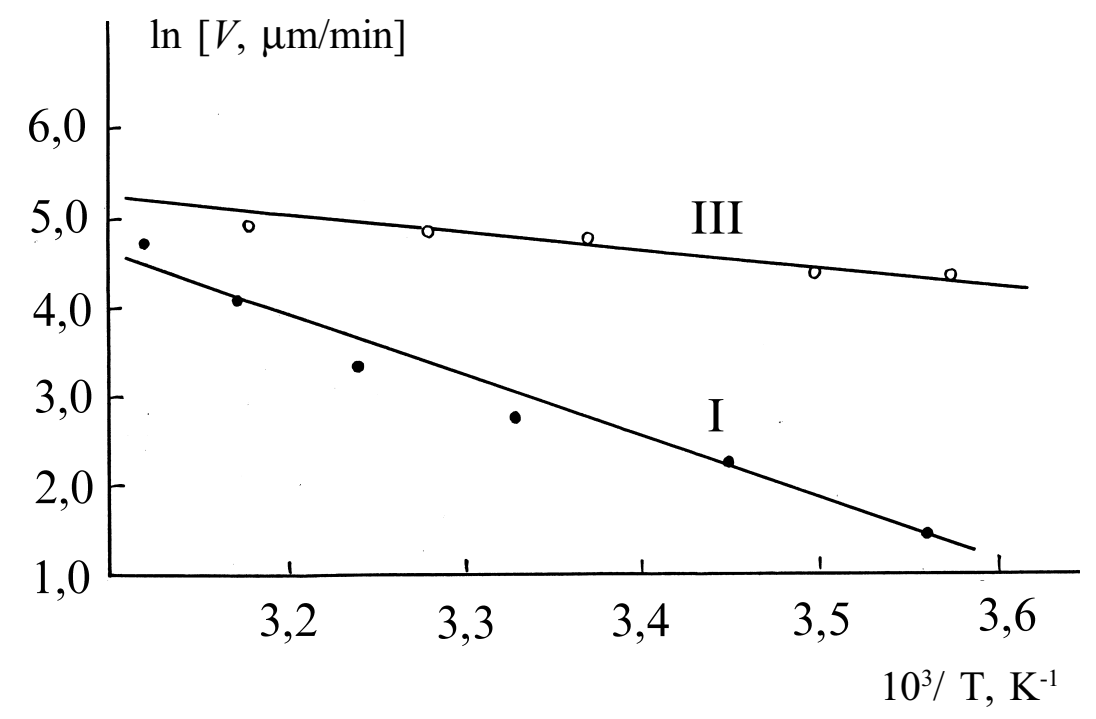

Fig. 3. Temperature dependence of the InAs dissolution rate for the solutions I and III of the $\mathrm{HNO}_{3}-\mathrm{HBr}-\mathrm{H}_{2} \mathrm{O}$ system (the composition of the solutions I and III is indicated in Fig. 1, a). 


\section{Z. F. Tomashik et al.: Dissolution of indium arsenide in nitric solutions of ...}

\section{Conclusions}

Depending on the $\left[\mathrm{HNO}_{3}\right] /[\mathrm{HBr}]$ ratio, dissolution of InAs in the solutions of the $\mathrm{HNO}_{3}-\mathrm{HBr}-\mathrm{H}_{2} \mathrm{O}$ system can be limited by kinetic on diffusion factors, or can be determined by some combined mechanism. In $\mathrm{HNO}_{3}-$ enriched solutions, the process of dissolution is controlled by the kinetic stages, while upon transition to $\mathrm{HBr}$ - and $\mathrm{H}_{2} \mathrm{O}$-enriched solutions the dissolution process is gradually moved to the diffusion region. Solutions of this system can be used for dynamic chemical polishing of InAs with a variable etching rate.

\section{References}

1. B. D. Luft, V. A. Perevoshchikov, L. N. Vozmilova et al.: Fizikokhimicheskie metody obrabotki poverkhnosti poluprovodnikov (Physical and chemical methods for treatment of semiconductor surfaces, in Russian). - Radio i Svyaz' Publ., Moscow, (1982).
2. V. A. Perevoshchikov: Processes of dynamic chemical polishing of semiconductor surfaces (in Russian) // Vysokochistye Veshchestva. 2, pp. 5-29 (1995).

3. L. N. Vozmilova, M. M. Berdichenko: A study of local GaAs and InP etching with dimethylformamide solution of bromine (in Russian) // Izvestiya AN SSSR. Neorganicheskie Materialy. 16(1), pp. 13-17 (1980)

4. S. Adochi, K. Oe: Chemical Etching Characteristic of (001) GaAs // J. Electrochem. Soc. 130(12), pp. 2427-2434 (1983).

5. T. Matsuoka, H. Nagai: InP Etchant for Submicron Patterns // J. Electrochem. Soc. 133(12), pp. 2484-2491 (1986).

6. P. H. L. Notten, A. A. J. M. Damen; The Electrochenistry of InP in $\mathrm{Br}_{2} / \mathrm{HBr}$ Solutions and its Relevance to etching Behaviour // Appl. Surf. Sci. 28, pp. 331-344 (1987).

7. S. N. G. Chu, C. M. Jodlauk, A. A. Ballman: New Dislocation Etchant for InP // J. Electrochem. Soc. 129(2), pp. 352-354 (1982).

8. V. N. Tomashik, A. A. Sava: Interaction of tellurium and tellurium-containing semiconducting compounds with nitric solutions of hydrobromic acid (in Russian) // Izvestiya AN SSSR. Neorganicheskie Materialy. 28(2), pp. 324-328 (1992).

9. A. A. Nemodruk: Analytical Chemistry of Antimony (in Russian). - Nauka Publ., Moscow, (1978). 